\title{
FINANCIAL HEALTH AND SENSE OF COHERENCE
}

\section{Authors:}

Antoni Barnard

Dorè Peters 2

Helene Muller ${ }^{3}$

\section{Affiliations:}

${ }^{1}$ Department of Industrial and Organisational

Psychology, UNISA,

South Africa

${ }^{2}$ Summit Financial Partners, South Africa

${ }^{3}$ Computer Services

Department, UNISA,

South Africa

\section{Correspondence to:}

Antoni Barnard

email:

barnaha@unisa.ac.za

Postal address:

PO Box 392, UNISA 0003 ,

Pretoria, South Africa

\section{Keywords:}

Employee wellness;

financial health

insurance industry;

industrial psychology

sense of coherence (SOC); quantitative-relational survey design

\section{Dates:}

Received: 31 Aug. 2009

Accepted: 18 Nov. 2009

Published: 04 June 2010

How to cite this article: Barnard, A., Peters, D., \& Mueller, H. (2010).

Financial health and sense of coherence. $S A$ Journal of Human Resource Management/SA Tydskrif vir Menslikehulpbronbestuur, 8(1), Art. \#247, 12 pages. DOI: 10.4102/sajhrm. v8i1.247

This article is available at: http://www.sajhrm.co.za

(C) 2010. The Authors. Licensee: OpenJournals Publishing. This work is licensed under the Creative Commons Attribution License.

\begin{abstract}
Orientation: This article reports on a quantitative-relational study addressing the impact of sense of coherence (SOC), which is a psychological-wellness construct, on the financial-health profile of employees in an insurance company.
\end{abstract}

Research purpose: The objective of the study was to explore the relationship between psychological wellness as operationalised in the SOC construct and in financial health.

Motivation for the study: Financial pressure can be a major stressor in the workplace, affecting employees' ability to function optimally. The debt crisis in South Africa is therefore necessitating employers to invest in the financial health of their employees. In light of the National Credit Act 34 of 2005, employers should, in fact, provide debt counselling to employees struggling with financial problems. In the South African context, however, studies investigating the potential influence of psychological-wellness constructs on financial health are lacking.

Research design, approach and method: A cross-sectional survey design was applied and a quantitative-relational approach followed. From the 1100 employees in a financial insurance company, 435 completed questionnaires were received.

Main findings: The empirical results indicated a significant relationship between the variables, confirming that a stronger SOC impacts positively on employees' financial health. A stronger SOC therefore relates positively to more effective debt management and retirement planning.

Practical/managerial implications: The findings emphasised the importance of debt management and retirement planning being addressed and integrated into employee-assistance strategies and programmes.

Contribution/value-add: This study is a significant step in addressing financial health from a psychological perspective.

\section{INTRODUCTION}

Turbulence and uncertainty in the international economic climate have been mirrored in the South African context over the past couple of years. Many have praised the good economic climate in South Africa since becoming a democracy. In retrospect, however, Havenga (2008) questioned the effect that low interest rates prior to 2008 have had on consumer expectations and spending behaviour. It seems that the little financial pressure that people experienced gave rise to an increase in spending behaviour and a concurrent increase in lending and household debt. The increase in interest rates, fuel price hikes, living expenses and the steep inflation rate have, since the beginning of 2008, increasingly put pressure on household-income spending. Despite relief in the form of lowered interest rates since December 2008 (Whitfield, 2009), financial pressure is being exacerbated by the lending culture that has evolved in the country. Recently, economists have been concerned that consumers will increase their debt loan until they can literally borrow no more (Enterprise Risk, 2008) and many agree that the bad debt situation in South Africa will remain serious for some time (Steyn, 2009; Whitfield, 2009).

According to South Africa's National Credit Regulator (NCR') (in Whitfield, 2009), household debt (such as mortgage, credit-card, leasing and instalment debt) deteriorated in the fourth quarter of 2008 and bad debt increased. During this time, Piliso (2008), reviewing a consumer-debt report, concluded that South Africans are trapped in the worst debt crisis yet. Moreover, a survey by Summit ${ }^{2}$ during September/November 2008 in the IT industry indicated that over-indebtedness remains a reality in many South African households. Summit's findings indicated that, for example, members of the higher-income group of the sample show lower financial health because they struggle to repay their debt. These findings seem to support the argument by Carrier and Maurice (1998) that dysfunctional spending behaviour is exhibited by people in all spheres of the economic continuum. Carrier and Maurice further suggested that spending behaviour is determined largely by psychological factors rather than by level of income.

Concern regarding consumer spending and over-indebtedness is also reflected in the institution of the National Credit Act 34 of 2005, which came into operation in June 2007 (Steyn, 2009). The purpose of the act is to assist consumers with their financial planning, especially with controlling their debt. According to the NCR, which is the regulator of the act (in Whitfield, 2009), more than 50000 consumers have applied for debt counselling. We agree with Carrier and Maurice (1998) that a better

1.Information on the functioning of the NCR can be accessed on their website at http://www.ncr.org.za

2.Summit is an independent company consisting of financial well-being experts focusing on improving people's quality of life through financial consulting, training and coaching. 
understanding of psychological factors impacting on one's financial health may improve the capacity of organisations, debt counsellors and employee-assistance consultants to provide financial assistance.

Financial pressure and especially debt can be a major source of stress in the workplace (Cox, Hooker, Markwick \& Reilly, 2009; Siahpush, Spittal \& Gopal, 2007). Bosman (2007) argued that employees' debt-related problems become the organisation's problems due to the fact that such strain affects employees' productivity and their ability to function optimally (also see HR Highway, 2007). Although the link between spending behaviour and psychological characteristics was noted by some (Burgess, 2005; Carrier \& Maurice, 1998; MacEwen, Barling, Kelloway \& Higginbottom, 1995), Carrier and Maurice (1998) strongly suggested that further research needs to be done on exploring the psychological aspects that may impact on spending behaviour to improve the organisation's efficiency in providing financial-planning assistance.

In view of the above, the purpose of this study was to explore the relationship between employees' financial health and their psychological wellness as operationalised in the sense of coherence (SOC) construct.

\section{Psychological wellness and sense of coherence}

From a holistic perspective, wellness is regarded as a complete state of well-being or of integrated optimal living in different spheres of life, including the physical (body), emotional, intellectual (mind), spiritual (spirit), work and social spheres (Csiernik, 1995; Els \& De la Rey, 2006; Myers \& Sweeney, 2005; Wissing, 2000). The scientific study of optimal living has a research record spanning over 36 years and includes numerous approaches, theories and concepts, currently regarded as constituting the field of positive psychology (Coetzee \& Viviers, 2007). As a result, various psychological wellness constructs have evolved, supporting the view that psychological wellness is a multidimensional phenomenon with optimal living at its core (Gropp, Geldenhuys \& Visser, 2007). A construct from the field of positive psychology of particular interest to this study is the salutogenic construct of SOC, identified by Antonovsky (1979) in his exploration of people's psychological coping According to Van Schalkwyk and Rothmann (2008), SOC has been the focus of much research, the usefulness of the construct being widely supported because it correlates strongly with health in general. SOC has also been a widely researched variable in South African research in the field of industrial and organisational psychology, both in the past (Strümpfer \& Wissing, 1998; Viviers \& Cilliers, 1999) and more recently (Herbst, Coetzee \& Visser, 2007; Nel, Crafford \& Roodt, 2004; Oosthuizen \& Van Lill, 2008; Van der Colff \& Rothmann, 2009; Van Schalkwyk \& Rothmann, 2008)

The salutogenic approach accepts that stress, uncertainty, trauma and other difficulties are an inevitable part of life in general and of work life in particular (Coetzee \& Cilliers, 2001; Oosthuizen \& Van Lill, 2008; Strümpfer, 1995). However, despite these life and work stressors (in the context of this study, for example, the economic climate and ensuing financial stress articulated above), people manage to control them and some even thrive under such difficult circumstances due to the strength of their SOC (Antonovsky, 1979). Antonovsky (1979, p. 123) defined SOC as 'a global orientation that expresses the extent to which one has a pervasive, enduring though dynamic feeling of confidence that one's internal and external environments are predictable and that there is a high probability that things will work out as well as expected'. He continued to explain that SOC represents a basic life orientation that enables one to consider the best coping strategy for a specific problem (Antonovsky, 1987). Similarly, Gropp et al. (2007) and Van Schalkwyk and Rothman (2008) referred to SOC as a general orientation to one's environment that serves as a source of general resistance resources in order to deal with life demands. As such, SOC facilitates one's ability to perceive and control the environment for meaningful and appropriate action (Van Schalkwyk \& Rothmann, 2008).

Salutogenic functioning and SOC in particular consist of three constructs - namely, comprehensibility, manageability and meaningfulness (Antonovsky \& Sourani, 1988; Coetzee \& Cilliers, 2001; Gropp et al., 2007; Herbst et al., 2007). The comprehensibility construct refers to a constructive cognitive function through which individuals perceive confronting environmental stimuli as understandable and constructive and they can use it to facilitate effective decision making. The manageability construct refers to the extent to which individuals perceive that their resources are adequate to meet the demands posed by external stressors and challenges. The meaningfulness construct refers to the extent to which individuals feel that life makes sense and that challenges and stimuli encountered are worthwhile to address and resolve.

\section{Financial health}

On the one hand, financial health implies a relatively objective meaning referring to the ability to manage income and expenses in a manner that results in an acceptably stable and manageable financial situation or what Whitfield (2009) referred to as 'normal economic activity', which includes a manageable debt situation. On the other hand, financial health also involves the subjective experience of financial well-being (compare Carrier \& Maurice, 1998; HR Highway, 2007). The subjective experience of financial well-being implies the perception of being able to manage a good and satisfactory living within the boundaries of one's income. In this regard, Siahpush et al. (2007, p. 2283) referred to 'material well-being', which they measured by ascertaining people's perceptions of their material well-being on a continuum ranging from being prosperous to being very poor. In summary, Cox et al. (2009, p. vi) defined financial wellbeing comprehensively as referring to 'subjective perceptions and objective indicators of individuals' personal financial status'.

Although general definitions of wellness specify optimal functioning with regard to the physical, emotional, intellectual, spiritual and social spheres of life, the financial aspects of one's life may definitely be included as an additional wellness dimension, as it also affects many other spheres of life, such as family and social life (Carrier \& Maurice, 1998) and work life (HR Highway, 2007)

\section{Problem statement and research objective}

The increasing economic pressure over the last couple of years is a reality, giving rise to employee debt, which should be managed by organisations to retain a psychologically and financially healthy workforce. According to HR Highway (2007), it is generally known that anyone under financial stress struggles to work optimally, affecting not only the individual's performance but also that of co-workers and, ultimately, of the organisation (also see Cox et al., 2009). Apart from demographic characteristics and personal financial behaviours that predict financial well-being (Cox et al., 2009), there is no evidence identifying particular psychological constructs that may relate to financial health. Due to the recognition of psychological strengths, such as SOC, in facilitating optimal living despite environmental challenges and stressors, it seems reasonable to question whether a strong SOC would enable a person to manage economic pressures more effectively than a person with a lower SOC.

In light of the above-stated research problem, the objective of this study was to explore the relationship between SOC and financial health. The following research hypotheses were formulated: 
Hypothesis 1: Respondents with a healthy financial profile present with a significantly higher SOC than those with an unhealthy financial profile.

Hypothesis 2: Respondents with a high SOC present with a significantly healthier financial health profile than those with a low SOC.

\section{RESEARCH DESIGN}

\section{Research approach}

A cross-sectional survey design was applied in this study and a quantitative-relational approach was followed, through which the statistical relationships between the relevant variables namely, SOC and financial health, were analysed. Data were collected by means of questionnaires.

\section{Research methodology \\ Sampling}

A population of 1100 employees at a financial insurance company was approached to partake in the study. All post levels were approached to ensure a representative sample and to adhere to the principles of a cross-sectional survey design. Participation was voluntary (convenience sampling) and 435 completed questionnaires were returned, constituting a $40 \%$ response rate.

\section{Measuring instruments \\ Orientation to Life Questionnaire (OLQ): Antonovsky (1987) constructed a 29-item scale to measure SOC as well as a 13- item format of the same scale, both of which are referred to as the OLQ. Various adapted forms of the OLQ have since been used (Van Schalkwyk \& Rothmann, 2008). In this study, SOC was measured by means of the shortened 13-item version of the OLQ. The OLQ-13 is a self-report questionnaire evaluating one's tendency to experience life, in general, as comprehensible, manageable and meaningful. The higher the score on the OLQ, the stronger the SOC. The reliability and validity of the OLQ- 13 were established in various previous studies (Antonovsky, 1993; Feldt \& Rasku, 1998; Muller, 2007; Sandell, Blomberg \& Lazar, 1998; Strümpfer \& Wissing, 1998; Van Schalkwyk \&} Rothmann, 2008).

Financial Health Survey (FHS): According to Cox et al. (2009), objective indicators of financial well-being include measures such as income, debt, savings, financial planning and budgeting as well as knowledge of financial services and products. The FHS was developed for this study based on various objective indicators of financial health and was used to gather data on the respondents' financial-health behaviour. The FHS includes seven biographical questions and six items describing a person's income status, debt situation, reason for over-indebtedness, financial planning in general as well as orientation towards retirement and saving.

\section{Data collection}

All the employees of the financial insurance company were invited to attend the launch of the company's financial-health services during a two-day health conference. Company management had been approached for consent for this study to be conducted. Among other activities, the employees were consequently personally invited to complete the measurement instruments. The ethical aspects of freedom of choice, confidentiality and privacy were addressed in the sense that participation was anonymous and vol untary. A trained assessor was available to each participant for guidance through the instructions and to answer any questions.

\section{Data-analysis methodology}

The research questions imbedded in the research objectives were addressed by implementing a logical sequence of statistical-analysis techniques as indicated in the following paragraphs. All analyses were performed with the Statistical Analysis System software package version 9.1 .

An exploratory analysis was first conducted on biographical and FHS data. The one-way frequency distributions of the sample demographics reflected in Table 1 were used to describe the sampled population of the insurance-company employees who participated in the study. Composite-frequency distributions calculated on the FHS variables provided an initial cursory overview of the general trend of the respondents' financial well-being. Three of the six non-biographical FHS variables were subsequently used to calculate a financial-health index (FH index) used in further analyses to explore the relationship between SOC and financial health. An intercorrelation matrix among FHS indicators was calculated to determine interrelationships.

An exploratory-factor analysis was conducted to investigate the underlying structure of the OLQ-13 response data. Structure verification was deemed necessary, since findings of other studies in literature indicated varying SOC data structures ranging from a single-factor structure (one general construct) to several-factor structures (specific SOC constructs). Factoranalysis results for a single-factor structure analysis and a three-factor structure analysis were therefore tested for internal-consistency reliability with scale-reliability testing. The best factor-structure option was selected based on internalconsistency reliability and, in the final preparatory analyses, a set of SOC scores per factor was derived (calculated per individual as the average response to all OLQ-13 questionnaireitem responses included in the factor). The general one-factor structure proved to be the best option. The single set of general SOC construct scores was then classified as representing a high or a low SOC according to a predetermined rule.

Once preparatory analyses of FHS and SOC data were completed, the relationship between financial health and SOC was addressed through analyses of variance (ANOVA) using the General Linear Model (GLM) approach; Bonferroni multiple-comparisons-of-means tests were conducted on the SOC general-construct scores. The two techniques established whether the SOC general construct had a significant effect on financial-health indicators and, once identified, how SOC affected financial health. Financial-health indicators were represented in a first ANOVA model by the FHS income variable, the calculated FH index, reason for over-indebtedness and age. In a second ANOVA model, financial-health indicators were represented by the FHS indicators income, debt situation, financial planning, reason for over-indebtedness and attitude towards retirement. The two ANOVA models were investigated to determine which ANOVA model explains the most variability in the set of general SOC scores. ANOVA thus established whether a statistically significant relationship between financial health and SOC existed. Multiple comparisons of means tests identified how SOC affected significant financialhealth indicators. In this way, the established relationship between financial health and SOC could be described.

In a concluding step, a financial-health profile of the respondents with a high/low SOC was extracted from two-way frequency tables as well as an SOC profile of the respondents with a healthy/unhealthy financial situation.

\section{RESULTS}

\section{Sample description}

The biographical properties of the respondents included in the study are presented in Table 1 and serve to describe the sampled population. 
TABLE 1

Sample characteristics $(n=435)$

\begin{tabular}{|c|c|c|c|c|c|}
\hline & \multirow[b]{2}{*}{ Category } & \multirow[b]{2}{*}{ Frequency } & \multirow[b]{2}{*}{$\%$} & \multicolumn{2}{|c|}{ Cumulative } \\
\hline & & & & Frequency & $\%$ \\
\hline \multirow[t]{6}{*}{ Age } & $<25$ & 98 & 23.73 & 98 & 23.73 \\
\hline & $26-35$ & 177 & 42.86 & 275 & 66.59 \\
\hline & $36-45$ & 92 & 22.28 & 367 & 88.86 \\
\hline & $46-55$ & 34 & 8.23 & 401 & 97.09 \\
\hline & $56+$ & 12 & 2.91 & 413 & 100.00 \\
\hline & Missing & 22 & & & \\
\hline \multirow[t]{5}{*}{ Population } & Black & 217 & 53.85 & 217 & 53.85 \\
\hline & Coloured & 50 & 12.41 & 267 & 66.25 \\
\hline & Indian & 60 & 14.89 & 327 & 81.14 \\
\hline & White & 76 & 18.86 & 403 & 100.00 \\
\hline & Missing & 32 & & & \\
\hline \multirow[t]{5}{*}{ \# of dependants } & None & 167 & 42.71 & 167 & 42.71 \\
\hline & $1-2$ & 165 & 42.2 & 332 & 84.91 \\
\hline & $3-4$ & 51 & 13.04 & 383 & 97.95 \\
\hline & $4+$ & 8 & 2.05 & 391 & 100.00 \\
\hline & Missing & 44 & & & \\
\hline \multirow[t]{4}{*}{ Marital status } & Single & 235 & 58.02 & 235 & 58.02 \\
\hline & Married & 144 & 35.56 & 379 & 93.58 \\
\hline & Divorced & 26 & 6.42 & 405 & 100.00 \\
\hline & Missing & 30 & & & \\
\hline \multirow[t]{3}{*}{ Gender } & Male & 129 & 33.16 & 129 & 33.16 \\
\hline & Female & 260 & 66.84 & 389 & 100.00 \\
\hline & Missing & 46 & & & \\
\hline \multirow[t]{3}{*}{ Household earner } & Yes & 148 & 38.24 & 148 & 38.24 \\
\hline & No & 239 & 61.76 & 387 & 100.00 \\
\hline & Missing & 48 & & & \\
\hline
\end{tabular}

The response group was relatively young, with $43 \%$ of the respondents falling in the 26-35-year-old age category, 24\% of the respondents being younger than 26 and only $33 \%$ being older than 35 . The Black population group was best represented in the sample (54\%), followed by the White population group (19\%), the Indian population group (15\%) and the Coloured population group (12\%). By far the majority of the respondents indicated that they had two or fewer or no dependants $(85 \%)$ which is in agreement with the relatively young age distribution of the sampled employees. This also coincides with the fact that the largest contingent of the respondents $(58 \%$, plus $6.42 \%$ if divorced respondents are included) indicated that they were single. The female/male composition of the sample group was $67 \%$ (female) and $33 \%$ (male), with only $38 \%$ of the respondents indicating that they were the only household earner.

\section{Exploratory analysis of FHS data}

The frequency distributions of the financial-health variables in Table 2 present a general picture of the respondents' financial health, indicating that $48 \%$ of the respondents earned less than R10 000 per month, while $52 \%$ earned more. Results further indicated that $57 \%$ reported manageable debt and $34 \%$ a more sombre debt situation.

Only 28\% indicated that they did active financial planning, with a substantial proportion (52\%) indicating their intent to plan but lacking the know-how. Almost $20 \%$ of the respondents had no clear financial direction. A total of $34 \%$ of the respondents indicated that they were over-indebted (146 out of the total of 435). These employees either struggled to pay their monthly debt instalments or could not afford to pay them at all. Primary reasons cited for over-indebtedness were unplanned expenses, forcing unaffordable loans $(33.45 \%)$ and irresponsible spending by themselves $(35 \%)$ or by their spouses $(6.18 \%)$ as well as an increase in interest rates, which had not been foreseen, catering for $23 \%$. A large proportion of the respondents $(61.23 \%)$ did not seem to plan sufficiently for retirement, with $38.77 \%$ able to save more than the minimum retirement premium each month The figures in the FHS therefore seemed to suggest a fairly unhealthy financial position among a substantial proportion of the sampled employees.

\section{Calculation of an FH index}

Since the relationship between SOC and financial health was the main purpose of the research, a single index of financial health - the FH index - was derived from four of the financialhealth indicators probed in the FHS questionnaire. Entering a single FH index variable into the regression model would later produce a parsimonious prediction model and an easily interpretable relationship between financial health and SOC. Cox et al. (2009) reported that financial health is predicted by people who do proactive financial planning and have manageable debt. Following this assumption, an FH index was subsequently calculated based on the indicators of proactive financial planning and manageable debt contained in the FHS categories of debt situation, financial planning and retirement planning. Another reason that the particular FHS indicators were selected was that significant correlations among them were established. These are presented in Table 3.

The FH index for each respondent was initially set to a value of six. Individual indices were derived by adding $2,1,-1$ or -2 to the value depending on the option selected for each of the three indicators mentioned above. A negative value was added to the initial index value if an option for an indicator was regarded as contributing to an unhealthy personal financial situation and a positive value was added if an option was regarded as contributing to a healthy personal financial situation. Table 4 provides a summative indication of the protocol that was followed in deriving the FH index for each participant.

The value of the FH index varies between 1 and 12. The respondents' index values were categorised as representing 
TABLE 2

Frequency of FHS indicators

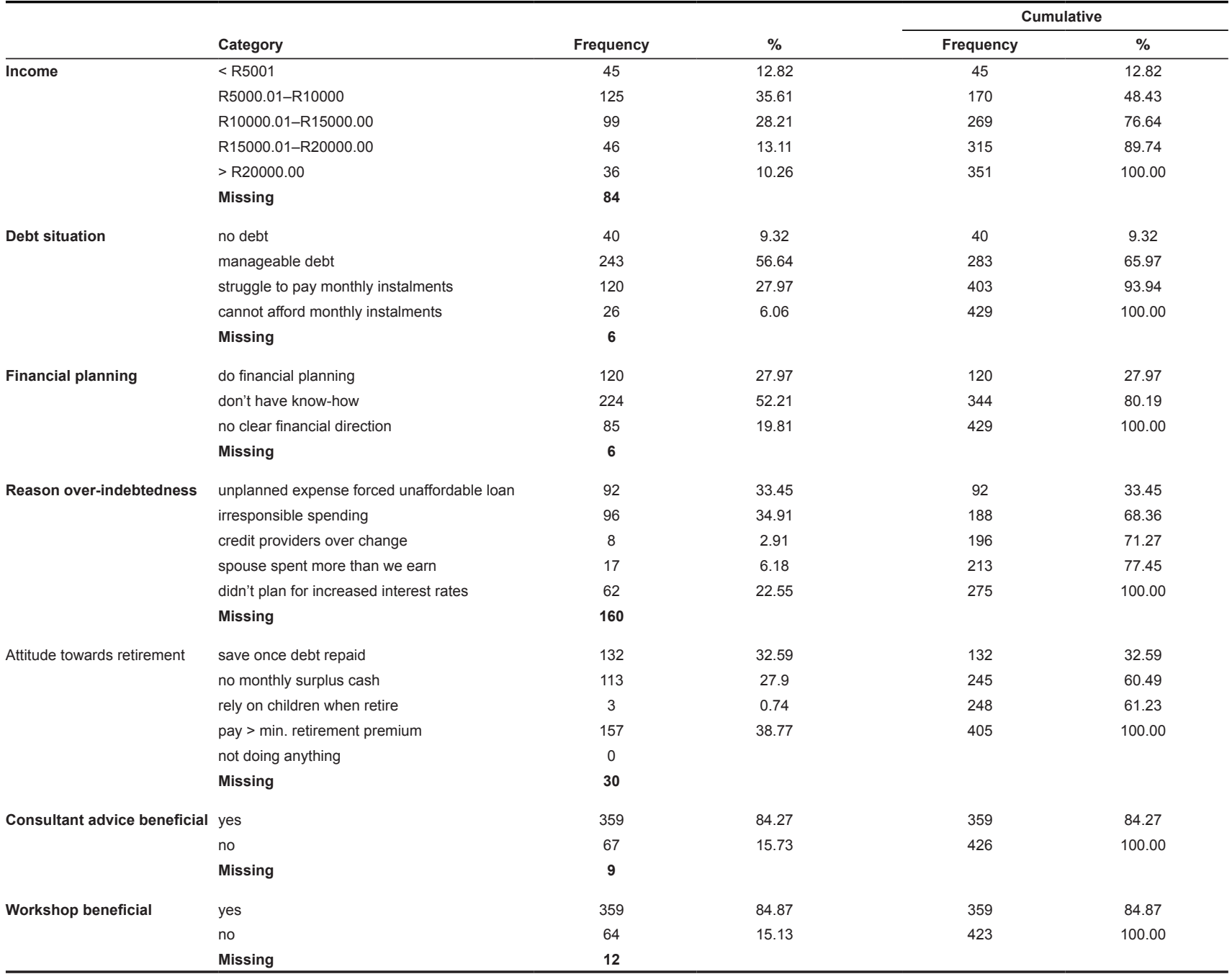

either a healthy, average or unhealthy financial situation depending on whether the individual FH indices fell between 1 and 4 (unhealthy), 5 and 7 (average) or 8 and 12 (healthy) below or above 5 .

\section{Factor analysis of OLQ-13 data}

A factor analysis was conducted on the OLQ-13 scores to investigate the underlying structure of the data. The Maximum Likelihood Method factor analysis with varimax rotation (orthogonal rotation) was initially used. Promax rotation (nonorthogonal rotation) was also investigated to accommodate the interrelationships between the constructs as mentioned by Antonovsky (1987).

Firstly, results from these analyses indicated, with statistical significance, that at least one factor could be assumed for the SOC data structure (the probability associated with the chi-square statistic of 1068.89 in the null hypothesis of no common factor structure was less than 0.0001). Secondly, however, additional results indicated that a large proportion of the variation in the SOC scores could be accounted for by three factors; scree-plot results also suggested the possibility of three factors. Analysis results thus offered the options of a one-factor or a three-factor data structure. The three-factor structure of the current research was compared against factors initially identified in research by Antonovsky (1987) as comprehensibility, manageability and meaningfulness. Table 5 summarises this comparison.
The comparison firstly indicated that the factor analysis in the current research excluded the contribution of three OLQ-13 questionnaire items (items 1, 4 and 7) from the factor structure due to their factor loadings being less than the critical value of 0.3. The comparison secondly indicated that aspects of the three factors agreed to some extent but that discrepancies among constructs were evident. Disparity could be ascribed to the sample size being relatively small (419) and to the intertwined nature of the three constructs described by Antonovsky (1987) and other researchers (Schumann, Hapke, Meyer, Rumpf \& John, 2003). According to Schumann et al. (2003), repeated factor analyses of the OLQ scale failed to identify distinctive separate factors representing the theoretically suggested three-construct structure of SOC. Originally, according to Antonovsky, a general SOC construct that can often be arranged according to three SOC components exists - namely, comprehensibility, manageability and meaningfulness. He did later, however, suggest that these three theoretical components should not be considered as subscales of the SOC measure and, based on a review of several studies, concluded that a single factor is more likely to result from factor analysis (Van Schalkwyk \& Rothmann, 2008). Muller (2007) also commented on studies confirming high intercorrelations among the three components.

The outcome of the comparison of the three constructs prompted the researchers to use the one-factor structure option - the general SOC construct - rather than the three-factor structure option in further analyses on the relationship between SOC and financial health. This decision was substantiated by 
TABLE 3

Intercorrelation Matrix of Fanancial Health Survey Indicators

\begin{tabular}{|c|c|c|c|c|c|}
\hline Spearman Probability $>|r|_{0}:=0$ Number & Debt & Plan & Over & Retire & Income \\
\hline Debt & 1.000 & 0.327 & -0.068 & - & -0.150 \\
\hline \multirow[t]{4}{*}{ Debt situation } & - & $<.0001$ & 0.260 & 0.323 & 0.005 \\
\hline & 429 & 428 & 274 & 5 & 349 \\
\hline & - & - & - & $<.0001$ & - \\
\hline & - & - & - & 4041 & - \\
\hline Plan & 0.327 & 1.000 & -0.072 & - & -0.145 \\
\hline \multirow[t]{4}{*}{ Financial planning situation } & $<.0001$ & - & 0.238 & 0.188 & 0.007 \\
\hline & 428 & 429 & 274 & 1 & 349 \\
\hline & - & - & - & 0.000 & - \\
\hline & - & - & - & 4041 & - \\
\hline Reason & -0.068 & -0.072 & 1.000 & 0.196 & 0.048 \\
\hline \multirow[t]{3}{*}{ Over-indebtedness } & 0.260 & 0.238 & - & 5 & 0.471 \\
\hline & 274 & 274 & 275 & 0.002 & 230 \\
\hline & - & - & - & 2652 & - \\
\hline Retire & - & - & 0.196 & 1.000 & 0.164 \\
\hline \multirow[t]{4}{*}{ Retirement planning } & -0.323 & -0.188 & 0.002 & - & 0.003 \\
\hline & $<.0001$ & 1 & 2652 & 4052 & 327 \\
\hline & 4041 & 0.000 & - & - & - \\
\hline & - & 4041 & - & - & - \\
\hline Income & -0.150 & -0.145 & 0.048 & 0.164 & 1.000 \\
\hline \multirow[t]{3}{*}{ Income } & 0.005 & 0.007 & 0.471 & 6 & - \\
\hline & 349 & 349 & 230 & 0.003 & 351 \\
\hline & - & - & - & 3287 & - \\
\hline
\end{tabular}

TABLE 4

Protocol followed in deriving an index of financial health

\begin{tabular}{|c|c|c|c|c|}
\hline & \multicolumn{2}{|c|}{ Add } & \multicolumn{2}{|c|}{ Subtract } \\
\hline & 1 & 2 & 1 & 2 \\
\hline Debt & Manageable debt & Have no debt & $\begin{array}{l}\text { Struggle with monthly } \\
\text { instalments }\end{array}$ & Cannot afford to repay \\
\hline Planning & - & Clear financial plan & - & No financial direction \\
\hline Retirement & Save once debt repaid & Save more than min. required & No cash surplus to save & I will rely on my children \\
\hline
\end{tabular}

TABLE 5

Comparison of Sense of Coherence constructs identified in current and other research

\begin{tabular}{lll}
\hline Factor & Current research* & Antonovsky (1987) \\
\hline 1(comprehensibility) & $8,9,11$ & $2,6,8,9,11$ \\
2(manageability) & $2,3,10$ & $3,5,10,13$ \\
3(meaningfulness) & $5,6,12,13$ & $1,4,7,12$ \\
$\boldsymbol{N}=\mathbf{4 3 5}$ & \\
\hline
\end{tabular}

internal-consistency reliability testing conducted both on the single factor of the one-factor structure option and on the three factors of the three-factor structure option suggested by the factor analysis results. The results of the scale-reliability testing are described in the next section.

\section{Scale-reliability testing on OLQ-13 response- item subsets}

Scale-reliability testing was conducted on the responses of each subset of the OLQ-13 questionnaire items identified in the factor analyses describing a factor in the SOC data structure. The subsets are given in Table 6. Scale-reliability testing evaluates internal-consistency reliability.

The internal-consistency reliability for each of the three subsets of questionnaire items comprising the factors of the threefactor SOC data structure was found to be unsatisfactory. This was expected due to the results of the previous factor-analysis studies mentioned above and because the factor analysis described in the preceding section indicated that constructs in the current analysis and those suggested by Antonovsky (1987) did not agree.

The internal-consistency reliability of the general SOC construct, identified in the single-factor SOC data structure, was, however, satisfactory, with a Cronbach alpha coefficient of 0.76 . The results are presented in Table 6 . The findings of this study also confirmed the high internal-consistency reliabilities (with Cronbach alpha values ranging between 0.84 and 0.93 ) found in several other studies mentioned by Muller (2007). This fact substantiated the decision to use the general SOC construct in further analysis.

A general SOC score was therefore calculated for each respondent as the mean response of the OLQ-13 questionnaireitem response ratings of each respondent. Since internalconsistency reliability had been established, it could be assumed that the mean SOC score would provide a reliable measure of the respondents' SOC. The construct mean scores for the relevant factors are also reported on in Table 6.

\section{Inferential analysis of the relationship between financial health and SOC}

ANOVA on general SOC scores: Model (income, FH index, reason, age)

ANOVA was conducted on the general SOC construct scores, with income, FH index (which represented the combined effects of debt, financial planning and retirement planning), reason for 
TABLE 6

Cronbach alpha associated with Sense of Coherence

\begin{tabular}{|c|c|c|c|}
\hline Construct & Subset of questionnaire items & Standardised Cronbach Alpha & Construct mean score \\
\hline Comprehensibility & $q 2, q 6, q 8, q 9, q 11$ & 0.61 & 20.22 \\
\hline Manageability & $q 3, q 5, q 10, q 13$ & 0.52 & 16.83 \\
\hline Meaningfulness & $q 1, q 4, q 7, q 12$ & 0.4 & 18.89 \\
\hline General Sense of Coherence (SOC) & $q 1-q 13$ & 0.76 & 55.89 \\
\hline
\end{tabular}

TABLE 7

ANOVA on Sense of Coherence (SOC) scores

\begin{tabular}{|c|c|c|c|c|c|}
\hline Source & DF & Sum of Squares & Mean Square & $F$-Value & $\operatorname{Pr}>F$ \\
\hline Model & 15 & 6048.895 & 403.260 & 5.86 & $<.0001$ \\
\hline Income & 1 & 403.167 & 403.167 & 5.86 & 0.017 \\
\hline Financial Health-index & 2 & 2902.891 & 1451.446 & 21.08 & $<.0001$ \\
\hline Reason & 3 & 1234.009 & 411.336 & 5.97 & 0.001 \\
\hline Age & 3 & 62.968 & 20.989 & 0.3 & 0.822 \\
\hline Age*Financial Health & 6 & 878.648 & 146.441 & 2.13 & 0.052 \\
\hline Error & 187 & 12875.706 & 68.854 & & \\
\hline Corrected Total $(N-1)$ & 202 & 18924.601 & & & \\
\hline
\end{tabular}

$\boldsymbol{R}$-Square $=0.319631 ;$ Coeff Var. $=15.79724 ;$ Root MSE $=8.297833 ;$ SOC Mean $=52.52709$

TABLE 8

Bonferroni multiple comparisons of means tests: Main effect Financial Health Survey (FHS) categories (income, FH-index, reason, age-by-FH-index) on Sense of Coherence (SOC)

\begin{tabular}{|c|c|c|c|c|c|c|}
\hline & Bon symbol & SOC Mean $^{\dagger}$ & $N$ & Income & FH-index & Reason for over-indebtedness \\
\hline \multirow[t]{2}{*}{ Isd = 2.3041 (Bonferroni) } & a & 54.840 & 94 & $>\mathrm{R} 10000$ & & \\
\hline & $\mathrm{b}$ & 50.532 & 109 & $<\mathrm{R} 10001$ & & \\
\hline \multirow[t]{3}{*}{ Isd $=.3 .4698$ (Bonferroni) } & a & 57.473 & 74 & & Healthy FH & \\
\hline & $\mathrm{b}$ & 51.653 & 72 & & Average $\mathrm{FH}$ & \\
\hline & c & 47.211 & 57 & & Unhealthy FH & \\
\hline \multirow[t]{4}{*}{ Isd = 5.4325 (Bonferroni) } & a & 55.898 & 49 & & & increased interest rates \\
\hline & a & 54.000 & 14 & & & spouse spent more than we earn \\
\hline & $a b$ & 53.693 & 75 & & & irresponsible spending \\
\hline & a & 48.323 & 65 & & & unplanned expense forced unaffordable loan \\
\hline
\end{tabular}

${ }^{\dagger}$ Means with the same letter are not significantly different

\begin{tabular}{llll}
\hline $\begin{array}{c}\text { Nature of significance of interaction effect Age*FH-index (matrices of t-tests } \\
\text { and probabilities not included, mean values with common symbols do not } \\
\text { differ significantly). Multiple comparisons of Least squares means (with } \\
\text { Bonferroni adjusted p-values) indicate interaction-effect categories for which } \\
\text { SOC means differ. }\end{array}$ \\
\hline Age & FH-index & SOC LS-Mean & Mean Number \\
\hline$<25$ & Average FH & $52.3911436 \mathrm{bc}$ & 1 \\
& Healthy FH & $55.8256134 \mathrm{bc}$ & 2 \\
& Unhealthy FH & $48.1189000 \mathrm{ac}$ & 3 \\
$26-35$ & Average FH & $53.1596147 \mathrm{bc}$ & 4 \\
& Healthy FH & $55.8430908 \mathrm{bc}$ & 5 \\
& Unhealthy FH & $48.8523849 \mathrm{ac}$ & 6 \\
& & & \\
$36-45$ & Average FH & $51.5856598 \mathrm{abc}$ & 7 \\
& Healthy FH & $59.8990565 \mathrm{~b}$ & 8 \\
& Unhealthy FH & $48.5640109 \mathrm{ac}$ & 9 \\
& & & \\
$46+$ & Average FH & $57.8946121 \mathrm{bc}$ & 10 \\
& Healthy FH & $57.7938849 \mathrm{bc}$ & 11 \\
& Unhealthy FH & $38.2642896 \mathrm{a}$ & 12 \\
\hline
\end{tabular}

indebtedness, age and interaction effects included in the model. The significance of models incorporating the other biographical variables as well was also investigated (including secondorder interaction effects). The first-mentioned model, however, provided the model of best fit and is reported on below.

The GLM approach to ANOVA was used, since the data was unbalanced. The ANOVA assumptions of the normality of residuals and of the homogeneity of variances were complied with. From the results presented in Table 7, general significance was established for the ANOVA model on the $0.1 \%$ level of significance with a model- $F$ statistical value of 5.86 . Income, FH index, reason for over-indebtedness and the interaction effect of age and FH index further proved to have a significant effect on SOC. A significance level of at least $5 \%$ was associated with the respective $F$ statistics. The $R$ square value of 0.3119631 furthermore indicated that the model explained $32 \%$ of the variability in the SOC scores. (The interaction effects that proved not to be significant were added to the error term.)

The ANOVA results thus established the significance of the effects of income, FH index, reason for over-indebtedness and age-by-FH-index interaction on SOC but did not, however, explain the nature of the relationship between SOC and statistically significant effects. The nature of the relationship was therefore investigated through Bonferroni multiplecomparisons-of-means tests for mean effects and the multiple comparison of least-square means (with the Bonferroni multiple-comparison adjustment for the $p$ values for the differences of LS means) for interaction effects.

Table 8 illustrates SOC means arranged according to income, FH index, reason for over-indebtedness and age-by-FH-index interaction categories and further illustrates that SOC mean scores differed significantly among the financially healthy (with an SOC mean of almost 58), average (with an SOC mean of 52) and financially unhealthy (with an SOC mean of 47) categories as well as between the higher-income (with an SOC mean of almost 55) and lower-income (with an SOC mean of almost 50) groupings. The tendency for higher SOC means to be associated with higher FH was repeatedly illustrated for each age category in the age-by-FH interaction table. The nature of the interaction significance was explained by the very low $46+$ age and unhealthy SOC mean (of 38.2), which differed significantly from the greater SOC means for all the financially healthy age groups (with mean scores of 56, 56, 60 and 58 for the age groups $<25,26-35,36-45$ and $46+$, respectively). The same holds true for the 46+ age and financially unhealthy respondents (with a mean of 38) and the financially average healthy age categories of $<25,26-35$ and $46+(52,53$ and 58 , respectively). 
TABLE 9

ANOVA on Sense of Coherence (SOC) and independent Financial Health Survey (FHS) variables

\begin{tabular}{|c|c|c|c|c|c|}
\hline Source & DF & Sum of Squares & Mean Square & $F$-Value & $\operatorname{Pr}>F$ \\
\hline Model & 14 & 6018.290 & 429.878 & 6.11 & $<.0001$ \\
\hline Income & 1 & 755.293 & 755.293 & 10.73 & 0.001 \\
\hline Debt & 3 & 1829.672 & 609.891 & 8.67 & $<.0001$ \\
\hline Over & 4 & 1553.834 & 388.459 & 5.52 & 0.000 \\
\hline Retire & 2 & 770.143 & 385.072 & 5.47 & 0.005 \\
\hline Income*Over & 4 & 589.300 & 147.325 & 2.09 & 0.083 \\
\hline Error & 190 & 13368.032 & 70.358 & & \\
\hline Corrected Total $(N-1)$ & 204 & 19386.322 & & & \\
\hline
\end{tabular}

$R$-Square $=0.31044 ;$ Coeff. Var. $=15.9408 ;$ Root MSE $=8.387971 ;$ SOC Mean $=52.61951$

TABLE 10

Bonferroni multiple comparisons of means tests: main effect Financial Health Survey (FHS) categories (income, debt situation, retirement planning, reason for over-indebtedness, ) on Sense of Coherence (SOC)

\begin{tabular}{|c|c|c|c|c|c|c|c|}
\hline & Bon symbol & Mean & $N$ & Income & Debt situation & Retirement planning & Reason for over-indebtedness \\
\hline \multirow{2}{*}{ Isd = 2.3192 (Bonferroni) } & A & 55.064 & 94 & >R10 000 & & & \\
\hline & B & 50.550 & 111 & $<$ R10 001 & & & \\
\hline \multirow[t]{4}{*}{ Isd = 6.7332 (Bonferroni) } & a & 56.360 & 89 & & manageable debt & & \\
\hline & a & 52.500 & 10 & & no debt & & \\
\hline & $a b$ & 50.483 & 89 & & struggle to handle debt & & \\
\hline & b & 44.294 & 17 & & cannot pay monthly inst & & \\
\hline
\end{tabular}

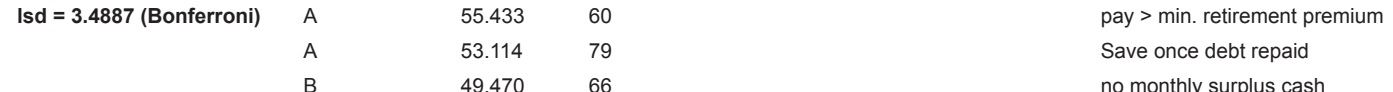

\begin{tabular}{|c|c|c|c|c|c|}
\hline \multirow[t]{5}{*}{ Isd = 9.2419} & A & 57.000 & \multicolumn{2}{|l|}{4} & credit providers over change \\
\hline & A & 55.898 & \multicolumn{2}{|l|}{49} & increased interest rates \\
\hline & A & 54.231 & \multicolumn{2}{|l|}{13} & spouse spent more than we earn \\
\hline & A & 53.703 & \multicolumn{2}{|l|}{74} & irresponsible spending \\
\hline & A & 48.323 & \multicolumn{2}{|l|}{65} & $\begin{array}{l}\text { unplanned expense forced } \\
\text { unaffordable loan }\end{array}$ \\
\hline \multicolumn{6}{|c|}{${ }^{\dagger} M$ Means with the same letter are not significantly different } \\
\hline \multicolumn{6}{|c|}{$\begin{array}{l}\text { Nature of significance of interaction effect Income*Reason (matrices of t-tests and probabilities not included, mean values with common symbols do not differ } \\
\text { significantly). Multiple comparisons of Least squares means (with Bonferroni adjusted p-values) indicate interaction-effect categories for which SOC means differ. }\end{array}$} \\
\hline \multicolumn{2}{|l|}{ Income } & \multicolumn{2}{|c|}{ Over } & SOC LS-MEAN & LS-MEAN Number \\
\hline \multirow[t]{5}{*}{$<$ R10001 } & & \multicolumn{2}{|c|}{ credit providers over change } & $50.3874307 \mathrm{bc}$ & 1 \\
\hline & & \multicolumn{2}{|c|}{ increased interest rates } & $54.7272436 \mathrm{bc}$ & 2 \\
\hline & & \multicolumn{2}{|c|}{ irresponsible spending } & $50.6941487 a c$ & 3 \\
\hline & & \multicolumn{2}{|c|}{ spouse spent more than we earn } & $45.1076743 b c$ & 4 \\
\hline & & \multicolumn{2}{|c|}{ unplanned expense forced unaffordable loan } & $45.3230749 b c$ & 5 \\
\hline \multirow[t]{5}{*}{$>$ R10000 } & & \multicolumn{2}{|c|}{ credit providers over change } & $72.5325227 a c$ & 6 \\
\hline & & \multicolumn{2}{|c|}{ increased interest rates } & $54.4887570 \mathrm{abc}$ & 7 \\
\hline & & \multicolumn{2}{|c|}{ irresponsible spending } & $52.8547269 b$ & 8 \\
\hline & & \multicolumn{2}{|c|}{ spouse spent more than we earn } & $55.2740552 \mathrm{ac}$ & 9 \\
\hline & & \multicolumn{2}{|c|}{ unplanned expense forced unaffordable loan } & 50.433 & 10 \\
\hline
\end{tabular}

\section{ANOVA on general SOC scores: Model (FHS indicators)}

In the prediction model discussed in the previous section the $\mathrm{FH}$ index was regarded as a parsimonious measure representing the FHS indicators of the level of indebtedness, financial planning and retirement planning. As an alternative to this relational model, an ANOVA was conducted on the SOC scores, with the individual FH effects of retirement planning, financial planning and debt situation included in the model. The effects of income, reason for over-indebtedness and second-order interaction effects were also entered into the model. In this model, there were 205 complete observation sets as opposed to the prediction model discussed in the previous section, with $N=203$ complete observations. In the latter analysis, biographical variables again did not prove to have a significant effect on SOC values and were therefore dropped from the model. The GLM approach to ANOVA was again used to accommodate the unbalanced data. ANOVA assumptions of the normality of residuals and the homogeneity of variances were validated.
The results of the ANOVA presented in Table 9 indicate general significance for the prediction model, with a probability of less than 0.0001 associated with the model- $F$ statistic of 6.11 , which was highly significant. Significant effects on at least the $1 \%$ level of significance were indicated for the four FHS explanatory variables of income, debt situation, reason for overindebtedness, retirement planning and the interaction effect of income-by-reason for over-indebtedness (with an $F$ statisticalvalues range of $10.73,8.67,5.52,5.47$ and 2.09 , respectively). Financial planning was dropped from the model, since no significant effect could be established for this explanatory variable. Since non-significance was indicated for the other interaction effects, their effect was added to the error term in the ANOVA. The $R$ square value of 0.310440 associated with this model implied that the model explained $31 \%$ of the variability in the SOC scores.

Once significant effects had been identified, the nature of the relationship between SOC and statistically significant financial- 
TABLE 11

Two way frequencies of Sense of Coherence (SOC)-categories cross referenced with Financial Health Survey (FHS) indicators and bio-data

\begin{tabular}{|c|c|c|c|c|c|}
\hline \multirow[t]{2}{*}{ Category } & \multicolumn{4}{|c|}{ SOC category } & \multirow[t]{2}{*}{$\begin{array}{l}\text { Statistic }{ }^{*} \text { and } \\
\text { trend test }\end{array}$} \\
\hline & Low & Medium & High & Total & \\
\hline \multicolumn{6}{|l|}{ Income } \\
\hline \multirow[t]{3}{*}{$<\mathrm{R} 10000$} & 64 & 72 & 33 & 169 & $17.36\left(0.0002^{* \star *}\right)$ \\
\hline & 18.29 & 20.57 & 9.43 & 48.29 & \\
\hline & 37.87 & 42.60 & 19.53 & - & \\
\hline \multirow[t]{3}{*}{ >R10 001} & 41 & 71 & 69 & 181 & $-3.62\left(0.0001^{* * *}\right)$ \\
\hline & 11.71 & 20.29 & 19.71 & 51.71 & \\
\hline & 22.65 & 39.23 & 38.12 & - & \\
\hline \multirow[t]{2}{*}{ Total } & 105 & 143 & 102 & 350 & \\
\hline & 30.00 & 40.86 & 29.14 & 100.00 & \\
\hline
\end{tabular}

Financial planning

Do financial planning

$\begin{array}{cccc}16 & 42 & 61 & 119 \\ 3.75 & 9.84 & 14.29 & 27.87 \\ 13.45 & 35.29 & 51.26 & -\end{array}$

Have aspirations, not know-how

$\begin{array}{llll}69 & 96 & 58 & 223\end{array}$

$\begin{array}{llll}16.16 & 22.48 & 13.58 & 52.22\end{array}$

$\begin{array}{llll}30.94 & 43.05 \quad 26.01\end{array}$

$\begin{array}{llllll}\text { No clear financial direction } & 38 & 33 & 14 & 85\end{array}$

$\begin{array}{llll}8.90 & 7.73 & 3.28 & 19.91\end{array}$

$\begin{array}{llll}44.71 & 38.82 & 16.47 \quad-\end{array}$

$\begin{array}{lllll}\text { Total } & 123 & 171 & 133 & 427\end{array}$

$28.81 \quad 40.05 \quad 31.15 \quad 100.00$

Retirement Planning

Save once debt repaid

$\begin{array}{llll}43 & 53 & 36 & 132\end{array}$

$\begin{array}{llll}10.75 & 13.25 & 9.00 & 33.00\end{array}$

$\begin{array}{llll}32.58 & 40.15 \quad 27.27 \quad-\end{array}$

$\begin{array}{llllll}\text { No monthly surplus cash } & 47 & 44 & 21 & 112\end{array}$

$\begin{array}{llll}11.75 & 11.00 & 5.25 & 28.00\end{array}$

$\begin{array}{llll}41.96 & 39.29 & 18.75\end{array}$

pay $>$ min. retirement

premium

Total

$\begin{array}{llll}16.67 & 39.1 \quad 44.23 \quad-\end{array}$

$\begin{array}{llll}116 & 158 & 126 & 400\end{array}$

$29.00 \quad 39.50 \quad 31.50 \quad 100.00$

FH-index

Unhealthy $\mathrm{FH}$

$\begin{array}{llll}48 & 29 & 5 & 82\end{array}$

$\begin{array}{llll}11.94 & 7.21 & 1.29 & 20.4\end{array}$

$\begin{array}{lll}58.54 & 35.37 \quad 6.10\end{array}$

$\begin{array}{lllll}\text { Average } \mathrm{FH} & 38 & 54 & 25 & 117\end{array}$

$\begin{array}{llll}3.45 & 13.43 & 6.22 & 29.1\end{array}$

$32.48 \quad 46.15 \quad 21.37$

$\begin{array}{lllll}\text { Healthy FH } & 30 & 77 & 96 & 203\end{array}$

$\begin{array}{llll}7.46 & 19.15 & 23.88 & 50.5\end{array}$

$\begin{array}{lll}14.78 & 37.93 & 47.29\end{array}$

Total

$\begin{array}{llll}116 & 160 & 126 & 402\end{array}$

$\begin{array}{llll}28.86 & 39.8 & 31.34 & 100.00\end{array}$

Debt consultation

\begin{tabular}{lccccc} 
Yes & 111 & 147 & 99 & 357 & $\mathbf{1 3 . 9 6}\left(\mathbf{0 . 0 0 0 9} \mathbf{9}^{* *}\right)$ \\
& 26.18 & 34.67 & 23.35 & 84.2 & \\
& 31.09 & 41.18 & 27.73 & - & \\
No & 10 & 24 & 33 & 67 & $\mathbf{- 3 . 1 8}\left(\mathbf{0 . 0 0 0 7}{ }^{* * *}\right)$ \\
& 2.36 & 5.66 & 7.78 & 15.8 & \\
Total & 14.93 & 35.82 & 49.25 & - & \\
& $\mathbf{1 2 1}$ & $\mathbf{1 7 1}$ & $\mathbf{1 3 2}$ & $\mathbf{4 2 4}$ & \\
& $\mathbf{2 8 . 5 4}$ & $\mathbf{4 0 . 3 3}$ & $\mathbf{3 1 . 1 3}$ & $\mathbf{1 0 0}$ & \\
\hline
\end{tabular}

TABLE 11 (Cont...)

Two way frequencies of Sense of Coherence (SOC)-categories cross referenced with Financial Health Survey (FHS) indicators and bio-data

\begin{tabular}{|c|c|c|c|c|c|}
\hline \multirow[t]{2}{*}{ Category } & \multicolumn{4}{|c|}{ SOC category } & \multirow{2}{*}{$\begin{array}{c}\text { Statistic }{ }^{*} \text { and } \\
\text { trend test }\end{array}$} \\
\hline & Low & Medium & High & Total & \\
\hline \multicolumn{6}{|c|}{ Debt Management ${ }^{++}$} \\
\hline \multirow[t]{3}{*}{ Yes } & 108 & 145 & 105 & 358 & $6.11\left(0.05^{*}\right)$ \\
\hline & 25.59 & 34.36 & 24.88 & 84.83 & \\
\hline & 30.17 & 40.50 & 29.33 & - & \\
\hline \multirow[t]{3}{*}{ No } & 11 & 26 & 27 & 64 & $-2.35\left(0.01^{* *}\right)$ \\
\hline & 2.61 & 6.16 & 6.40 & 15.17 & \\
\hline & 17.19 & 40.63 & 42.19 & & \\
\hline \multirow[t]{2}{*}{ Total } & 119 & 171 & 132 & 422 & \\
\hline & 28.20 & 40.52 & 31.28 & 100.00 & \\
\hline
\end{tabular}

Population group

Black

$\begin{array}{llll}78 & 87 & 49 & 214\end{array}$

$\begin{array}{llll}19.50 & 21.75 & 12.25 & 53.50\end{array}$

$\begin{array}{llll}36.45 & 40.65 & 22.90 & -\end{array}$

Coloured

$\begin{array}{llll}15 & 23 & 12 & 50\end{array}$

$\begin{array}{llll}3.75 & 5.75 & 3.00 & 12.50\end{array}$

$\begin{array}{llll}30.00 & 46.00 \quad 24.00 \quad-\end{array}$

Indian

$\begin{array}{llll}16 & 20 & 24 & 60\end{array}$

$\begin{array}{llll}4.00 & 5.00 & 6.00 & 15.00\end{array}$

$\begin{array}{lll}26.67 & 33.33 \quad 40.00 \quad-\end{array}$

White

$\begin{array}{llll}7 & 30 & 39 & 76\end{array}$

$\begin{array}{llll}1.75 & 7.50 & 9.75 & 19.00\end{array}$

$\begin{array}{llll}9.21 & 39.47 \quad 51.32 \quad-\end{array}$

$\begin{array}{lllll}\text { Total } & 116 & 160 & 124 & 400\end{array}$

$\begin{array}{llll}29.00 & 40.00 & 31.00 & 100.00\end{array}$

Marital status

Single

$\begin{array}{llll}82 & 87 & 65 & 234\end{array}$

$\begin{array}{llll}20.40 & 21.64 & 16.17 & 58.21\end{array}$

$\begin{array}{llll}35.04 & 37.18 & 27.78 \quad \text { - }\end{array}$

Married

$\begin{array}{llll}27 & 62 & 53 & 142\end{array}$

$\begin{array}{llll}6.72 & 15.42 & 13.18 & 35.32\end{array}$

$\begin{array}{llll}19.01 & 43.66 \quad 37.32 \quad-\end{array}$

Divorced

$\begin{array}{llll}8 & 12 & 6 & 26\end{array}$

$\begin{array}{llll}30.77 \quad 46.15 & 23.08 \quad-\end{array}$

$\begin{array}{llllll}\text { Total } & 117 & 161 & 124 & 402\end{array}$

$\begin{array}{llll}29.10 & 40.05 & 30.85 & 100\end{array}$

${ }^{*}$ Chi-square statistic (and probability); ${ }^{+Z}$-statistic trend test (and probability); ${ }^{++}$Workshop

health effects was further investigated through Bonferroni multiple-comparisons-of-means tests.

Table 10 illustrates the SOC means arranged according to the categories of the main effects of the FHS indicators and illustrates the categories of the SOC mean scores that differ significantly among the various indicators of financial health. The respondents in the > R10 000 income bracket displayed a significantly higher SOC (55.06) than the respondents in the $<$ R10 001 bracket, with an SOC mean score of 50.55. The respondents with manageable debt had a significantly higher SOC (56.36) than the respondents who claimed to have no debt (with an SOC mean score of 52.5). Those who struggled to handle their debt had an even lower SOC mean score of 50.9. In terms of debt situation, those respondents who could not pay their monthly instalments displayed the lowest SOC of all (SOC mean $=44.29$ ).

Reason for over-indebtedness also showed significant differences in mean SOC scores. Interestingly, the respondents who ascribed their over-indebtedness to credit providers who overcharged on interest and to increased interest rates displayed 
a significantly higher SOC (57.2 and 55.9, respectively). Lower SOC mean scores were found for people who had unplanned expenses $(\mathrm{SOC}=48)$ and who declared their debt to be due to irresponsible spending $(\mathrm{SOC}=53.7)$. The table of means furthermore indicated that those respondents who paid a higher retirement premium than the minimum required and those planning to invest more once debt was repaid had a statistically significantly higher SOC (55.4 and 53.11) than those who had no surplus cash on a monthly basis to invest in their retirement planning (mean SOC of 49.47)

The nature of significant income-by-reason-for-overindebtedness interaction is explained in Table 10 by a very low SOC mean score of 45.32 for the lower-income respondents who had unexpected expenses and unaffordable loans. The mean differed significantly from all the higher income-indebted categories (except higher income, unplanned expenses).

\section{Profile of respondents with a high or low SOC}

On the strength of the significant relationship found between SOC and financial-health indicators, a financial-health or demographic profile of respondents with a high or low SOC was deduced from the two-way frequency tables and associated Pearson chi-square and Cochran-Armitage trend tests (where applicable). This is presented in Table 11.

By comparing the within-category ratios for each of the biographical attributes and financial-health indicators for the high and low SOC respondents, the profile of high SOC respondents emerged from Table 11 as respondents who more often

- fell into the higher-income bracket $(69 / 33=$ approximately 2 , as opposed to $41 / 64=0.64$ for the low SOC group)

- did more constructive financial planning (as opposed to respondents with no direction) $(61 / 14=4.36$, as opposed to $16 / 38=0.42$ for the low SOC group)

- planned constructively for retirement (the ratio of paying a larger premium to save once debt was paid off was 69/36 $=1.92$, as opposed to $26 / 43=0.60$ for the low SOC group)

- were financially healthy (as illustrated by the abovementioned specific financial-health indicators and the healthy/unhealthy ratio of $96 / 5=19.2$ for the high SOC respondents, as opposed to $30 / 48=0.63$ for the low SOC respondents)

- made use of a debt consultant, but proportionately significantly less often than the low SOC group $(99 / 33=3$ as opposed to $111 / 10=11$ )

- benefited from attending debt-management workshops but proportionately significantly less so than the low SOC group $(105 / 27=3.89$ as opposed to $108 / 11=9.81)$

- were either White or Indian (with a high SOC to a low SOC for Whites with $39 / 7=5.6$, for Indians with $24 / 16=1.5$, for Coloureds with $12 / 15=0.80$ and for Blacks with $49 / 78=$ $0.63)$ and

- were married (the married to not-married ratio was 142/260 $=0.54$ for the high SOC group, as opposed to the ratio of $27 / 90=0.3$ for the low SOC group) .

By observing the same within-category ratios for each of the attributes for the high and low SOC respondents as above, it can be seen that a significantly greater proportion of respondents (that is a statistically significant proportion) with a poor SOC tended

- to fall into the lower-income group $(<$ R10 000 per month)

- not to practise active financial planning (not to have aspirations and did not know how to work towards their goals or had no clear financial vision)

- not to plan actively for retirement (they would start saving once debt was repaid and/or they had no monthly surplus cash available to plan with)

- to have a financially unhealthy situation (with an FH index below 5)
- to indicate that they would benefit from the advice of a debt counsellor and from attending a debt-management workshop

- to be Black or Coloured and

- to be single or divorced.

\section{Profile of respondents with a healthy or unhealthy financial profile}

The significant distribution differences in the SOC scores for financially healthy, average and financially unhealthy respondents are indicated in Table 12. The accompanying trend test identified the established distribution difference as a significant difference in the trend between the financially healthy and the financially unhealthy respondents. By examining the two SOC distributions, a lag in the SOC values can be detected. The unhealthy financial-health distribution tends to be spread over an SOC range of approximately 31-60, while the healthy $\mathrm{FH}$-index distribution tends to range between 51 and at least 80 . The deduction can be made that the SOC of the respondents who were financially unhealthy was, on average, lower than that of the financially healthy respondents (the ANOVA results in Table 8 verify this, showing significantly different SOC score means of 57.47 [for the healthy FH index] and 47.21 [for the unhealthy FH index]).

\section{DISCUSSION}

The primary objective of this study was to explore the relationship between SOC and financial health. Both hypotheses initially formulated in this study were accepted. A statistically significant relationship was found between SOC and financial health, highlighting the importance of approaching employees' financial health not only from an economic perspective but also from a psychological perspective. Research linking financial health to psychological wellness in the South African context is lacking and this research initiates studies in this regard.

\section{Integration of results}

Differences in the financial-health profile of people with a high SOC and people with a low SOC were explored, as was the SOC distribution of the respondents exhibiting a healthy financial profile as opposed to those exhibiting an unhealthy financial profile. Prior to the relational investigation between the two constructs, a factor analysis and an item analysis on OLQ-13 items were conducted. Results support the use of a single general SOC construct in further comparative analyses with FHS indicators, as opposed to the use of the 3-factor model initially suggested by Antonovsky (1987). Scale-reliability testing furthermore confirms that a general SOC score would provide a reliable measure of respondents' SOC.

When comparing various FHS indicators with SOC, severa influential and statistically significant effects were identified. The results with regard to an overall FH index show that the respondents with a healthier overall financial profile display a significantly higher SOC than the respondents with an unhealthy financial profile. This implies that people with a higher SOC probably have a greater ability to mobilise and generate resources to cope with financial pressure in a proactive manner. They may also tend to perceive themselves as able to cope with financial demands, thus strengthening their ability to remain financially healthy. By further implication, one can expect employees with a higher SOC to react more positively to difficult financial times.

Specific FHS indicators, such as income, debt management, over-indebtedness and retirement planning, also show significant effects on SOC mean scores and, together, explain $31 \%$ of the variance in SOC scores. The result of the ANOVA directly addresses the research question regarding a 
TABLE 12

Sense of Coherence (SOC) distribution of financially healthy, average or unhealthy respondents

\begin{tabular}{|c|c|c|c|c|}
\hline \multirow[t]{2}{*}{ General SOC score } & \multicolumn{3}{|c|}{ Financial Health $(\mathrm{FH})$-index } & \multirow[t]{2}{*}{ Total } \\
\hline & Unhealthy & Average & Healthy & \\
\hline \multicolumn{5}{|l|}{$11-20$} \\
\hline Frequency & 2 & 0 & 0 & 2 \\
\hline$\%$ & 0.5 & 0 & 0 & 0.5 \\
\hline Row \% & 100 & 0 & 0 & \\
\hline \multicolumn{5}{|l|}{$21-30$} \\
\hline Frequency & 4 & 0 & 2 & 6 \\
\hline$\%$ & 1 & 0 & 0.5 & 1.49 \\
\hline Row \% & 66.67 & 0 & 33.33 & \\
\hline \multicolumn{5}{|l|}{$31-40$} \\
\hline Frequency & 11 & 9 & 2 & 22 \\
\hline$\%$ & 2.74 & 2.24 & 0.5 & 5.47 \\
\hline Row \% & 50 & 40.91 & 9.09 & \\
\hline \multicolumn{5}{|l|}{$41-50$} \\
\hline Frequency & 31 & 29 & 26 & 86 \\
\hline$\%$ & 7.71 & 7.21 & 6.47 & 21.39 \\
\hline Row \% & 36.05 & 33.72 & 30.23 & \\
\hline \multicolumn{5}{|l|}{$51-60$} \\
\hline Frequency & 29 & 54 & 77 & 160 \\
\hline$\%$ & 7.21 & 13.43 & 19.15 & 39.8 \\
\hline Row \% & 18.13 & 33.75 & 48.13 & \\
\hline \multicolumn{5}{|l|}{$61-70$} \\
\hline Frequency & 4 & 16 & 70 & 90 \\
\hline$\%$ & 1 & 3.98 & 17.41 & 22.39 \\
\hline Row \% & 4.44 & 17.78 & 77.78 & \\
\hline \multicolumn{5}{|l|}{$71-80$} \\
\hline Frequency & 1 & 7 & 20 & 28 \\
\hline$\%$ & 0.25 & 1.74 & 4.98 & 6.97 \\
\hline Row \% & 3.57 & 25 & 71.43 & \\
\hline \multicolumn{5}{|l|}{$81-91$} \\
\hline Frequency & 0 & 2 & 6 & 8 \\
\hline$\%$ & 0 & 0.5 & 1.49 & 1.99 \\
\hline Row \% & 0 & 25 & 75 & \\
\hline \multirow[t]{2}{*}{ Total } & 82 & 117 & 203 & 402 \\
\hline & 20.4 & 29.1 & 50.5 & 100 \\
\hline \multicolumn{5}{|c|}{$\begin{array}{l}\text { Note: } F H \text {-index: } 1-4=\text { unhealthy; } 5-7=\text { average financial health; } 8-12=\text { financially health } \\
\text { Frequency Missing }=33\end{array}$} \\
\hline \multicolumn{5}{|c|}{$\begin{array}{l}\begin{array}{l}\text { Pearson's chi-sq test for three categories of healthy/ average and unhealthy } \\
\text { financial positions }\end{array} \\
\end{array}$} \\
\hline Statistic & DF & Value & Prob & \\
\hline Chi-Square & 14 & 91.458 & $<0.0001$ & \\
\hline \multicolumn{5}{|c|}{ Cochran Armitage trend test for the categories of healthy to unhealthy } \\
\hline Z statistic & & -7.518 & $<0.0001$ & \\
\hline
\end{tabular}

relationship between SOC and financial health and confirms that a statistically significant relationship exists between SOC and the FHS indicators of income, debt situation, reason for over-indebtedness and retirement planning. The respondents in the higher-income bracket display a significantly higher SOC than the respondents in the lower-income bracket. This is contrary to the findings of an initial pilot study mentioned at the onset of this article, which suggested that higher-income group respondents exhibited less financial health. The reason for the different finding may, however, be related to the moderating effect of a very small sample size used in the pilot study.

Further results in this study are in agreement with the pilotresearch findings. The respondents who manage their debt responsibly have a significantly higher SOC than those unable to manage their debt and the respondents' SOC is also significantly higher when they have no debt. The findings furthermore indicate that those respondents presenting with healthier retirement planning have a significantly higher SOC than those exhibiting poor retirement planning. The fact that various reasons for over-indebtedness are significantly related to SOC is interesting. The results seem to indicate that motivations underlying over-indebtedness relating to impulsive and irresponsible spending behaviour are related to a lower SOC.

Similar findings result from the analysis of the financialhealth profile of the respondents with a high versus a low SOC and from analysing the differences in the SOC mean scores for the financially healthy versus the financially unhealthy respondents. The financial profile of the respondents with a high SOC tend to display more financially healthy characteristics, such as good debt management and proactive retirement planning. The lower SOC respondents do not seem to practise active retirement planning despite aspirations to do so and seem to lack control over their debt situation.

The frequency distributions on the FHS indicators suggest that a generally unhealthy financial position is evident among the participants in this sample. The reported findings should, however, be interpreted with caution. The fact that the respondents are fairly young, unattached, not the only household earners and have two or fewer dependants could also affect the outcome of the relationship between SOC and financial health because the sampled population does not represent the section of the population most consumed by family and financial responsibilities. These findings do, however, concur with literature reported by Cox et al. (2009) in that people with poor financial well-being are more likely to be young, single and with lower incomes. According to Cox et al., those with better financial-health profiles are older and married or living with a partner and fall into higher-income brackets.

\section{Managerial implications}

From a practical perspective, it seems evident from the findings of this study that companies should focus holistically and proactively on the financial health of their employees. Debt and retirement-planning counselling may be more effective if integrated with aspects addressing employees' sense of self and confidence in their coping resources. It is also suggested that the continuous development of employees' psychological wellness may proactively lower the probability of their developing financial problems. Interventions aimed at enhancing employee wellness should integrate financial health as a core area to be addressed and employee-assistance programmes should have financial health as an integral part of their operations.

\section{Possible limitations of the study}

Due to the fact that financial health is a fairly unexamined phenomenon in the field of industrial and organisational psychology, financial-health indicators included in the FHS may have been limited and other meaningful indicators may have been overlooked.

The value of this study lies in the fact that it explores financial health as a potential variable of workplace well-being that has not been studied before in the South African context and that has become a dire reality for employees and employers alike.

\section{Suggestions for future research}

The SOC profiling described in this study is based on individual and on separate SOC cross-classification, with other financialhealth and biographical variables. It is suggested that, in followup research, the joint effect of these cross-classifications and their interactions should be investigated by means of a dataclassification method, such as a decision tree algorithm. The chi-square interaction detection method is an example of this particular technique. 
Follow-up studies in which additional financial-health indicators are explored, such as specifying the nature of debt (mortgages, credit cards and other) and specific financial-planning behaviours (budgeting, saving etc.), are recommended. The construct of financial health also needs to be explored further, as it may entail more aspects than explored in this study.

\section{Conclusion}

As suggested by Cox et al. (2009), studies exploring people's personal competence in handling financial matters would enhance employers' ability to customise interventions targeted at improving the financial health of their employees. Organisations will ultimately benefit, as financially healthy employees are significantly more productive than their counterparts (Cox et al., 2009).

\section{REFERENCES}

Antonovsky, A. (1979). Health, stress and coping. San Francisco: Jossey-Bass.

Antonovsky, A. (1987). Unraveling the mystery of health: How people manage stress and stay well. San Francisco: JosseyBass.

Antonovsky, A. (1993). The structure and properties of the sense of coherence scale. Journal of Science and Medicine, 36 , $725-733$

Antonovsky, A., \& Sourani, T. (1988). Family sense of coherence and family adaptation. Journal of Marriage and the Family, 50(1), 79-92.

Bosman, P. (2007, Sept/Oct). Employee assistance and the new National Credit Act. Professional Accountant, 34 336.

Burgess, S.M. (2005). The importance and motivational content of money attitudes: South Africans with living standards similar to those in industrialised Western countries. South African Journal of Psychology, 35(1), 106-126.

Carrier, L., \& Maurice, D. (1998). Beneath the surface: The psychological side of spending behaviours. Journal of Financial Planning, 11(1), 94-98.

Coetzee, S., \& Cilliers, F. (2001). Psychofortology: Explaining coping behaviour in organisations. The IndustrialOrganisational Psychologist, 38(4), 62-68.

Coetzee, S., \& Viviers, R. (2007). An overview of research on positive psychology in South Africa. South African Journal of Psychology, 37(3), 470-490.

Cox, A., Hooker, H., Markwick, C. \& Reilly, P. (2009). Financial well-being in the workplace. Research report 464. Sussex: Institute for Employment Studies.

Csiernik, R. (1995). Wellness, work and employee assistance programming. Employee Assistance Quarterly, 11(2), $1-13$.

Els, D.A., \& De la Rey, R.P. (2006). Developing a holistic wellness model. SA Journal of Human Resource Management, 4(2), 4656.

Debt woes for SA. (2008). Enterprise Risk, 2(6), 37-38.Retrieved May, 22, 2009, from http://www.sabinet.co.za/abstracts/ sh_eprise/sh_eprise_v2_n6_a15.html

Feldt, T., \& Rasku, A. (1998) The structure of Antonovsky's Orientation to Life Questionnaire. Personality and Individual Differences, 25(3), 505-516.

Gropp, L., Geldenhuys, D., \& Visser, D. (2007). Psychological wellness constructs: Relationships and group differences. $S A$ Journal of Industrial Psychology, 33(3), 24-34.
Havenga, R. (2008). The current economic situation: Not all bad news. Management Today, 24(4), 5.

Herbst, L., Coetzee, S. \& Visser, D. (2007). Personality, sense of coherence and the coping of working mothers. SA Journal of Industrial Psychology, 33(3), 57-67.

Employee debt affects you. (2007) HR Highway, 1(20), 18-19. Retrieved May, 22, 2009, from http://www.sabinet.co.za/ abstracts/sh_hrh/sh_hrh_v1_n2_a8.xml

MacEwen, K.E., Barling, J., Kelloway, E.K., \& Higginbottom, S.F. (1995). Predicting retirement anxiety: The roles of parental socialization and personal planning. The Journal of Social Psychology, 135(2), 203-213.

Muller, Y. (2007). Sense of coherence and employees' experience of helping and restraining factors in the working environment. Unpublished master's thesis, North-West University, Potchefstroom, South Africa.

Myers, J.E., \& Sweeney, T.J. (2005). Counselling for wellness: Theory, research and practice. Alexandria, VA: American Counselling Association.

Nel, D.J., Crafford, A., \& Roodt, G. (2004). The relationship between sense of coherence and goal setting. SA Journal of Industrial Psychology, 30(2), 46-55.

Oosthuizen, J.D., \& Van Lill, B. (2008). Coping with stress in the workplace. SA Journal of Industrial Psychology, 34(1), 64-69.

Piliso, S. (2008, 8 November). Debt nightmare. Sunday Times, n.p.

Sandell, R., Blomberg, J., \& Lazar, A. (1998). The factor structure of Antonovsky's Sense of Coherence Scale in Swedish clinical and nonclinical samples. Personality and Individual Differences, 24(5), 701-711.

Schumann, A., Hapke, U., Meyer, C., Rumpf, H.J. \& John, U. (2003). Measuring sense of coherence with only three items: A useful tool for population surveys. British Journal of Health Psychology, 8(4), 409-421.

Siahpush, M., Spittal, M., \& Gopal, G.K. (2007). American Journa of Public Health, 97(12), 2281-2287.

Steyn, G. (2009, 14 May). Focus on de-leveraging. Finweek, p. 43.

Strümpfer, D.J.W. (1995). The origins of health and strength: From 'salutogenesis' to 'fortigenesis'. South African Journal of Psychology, 25(2), 81-89.

Strümpfer, D.J.W., \& Wissing, M.P. (1998). Review of South African data on the sense of coherence scale as a measure of fortigenesis and salutogenesis. Paper presented at the National Congress of the Psychology Society of South Africa, Durban, South Africa.

Van der Colff, J.J., \& Rothmann, S. (2009). Occupational stress, sense of coherence, coping, burnout and work engagement of registered nurses in South Africa. SA Journal of Industrial Psychology, 35(1), 1-10.

Van Schalkwyk, L., \& Rothmann, S. (2008). Validation of the orientation to life questionnaire (OLQ) in a chemical factory. SA Journal of Industrial Psychology, 34(2), 3139.

Viviers, A.M., \& Cilliers, F. (1999). The relationship between salutogenesis and work orientation. SA Journal of Industrial Psychology, 25(1), 27-32.

Whitfield, B. (2009, 19 March). Bad debt rising. Finweek, p.

Wissing, M.P. (2000, May). Wellness: Construct clarification and a framework for future research and practice. Paper presented at the First South African National Wellness Conference, Port Elizabeth, South Africa. 